\title{
Unmentionables: Some Remarks on Taboo
}

\author{
Stefano Predelli*
}

Received: 20 October 2020 / Accepted: 10 May 2021

\begin{abstract}
This paper discusses the phenomenon of linguistic taboo. It contrasts that phenomenon with the truth-conditional and non-truthconditional dimensions of meaning, paying particular attention to slurs and coarseness. It then highlights the peculiarities of taboo and its meta-semantic repercussions: taboo is a meaning-related feature that is nevertheless directly associated with the tokening process. In the conclusion, it gestures to the role of taboo within a theory of linguistic action and the standard framework for conversational exchanges. On these results, I am going to end by looking at some of the harms that epistemic injustice inflicts upon its victims.
\end{abstract}

Keywords: Taboo; non-truth-conditional meaning; derogation; coarseness; register; David Kaplan.

Here is a (vague) truism: our utterances are subject to a type of normative evaluation independent from the information they encode. In what follows, I discuss this idea by focusing on a peculiar phenomenon, linguistic taboo.

There are several reasons why taboo, in my sense of that term, is a theoretically interesting affair. For one thing, it seems partially related with

* University of Nottingham

(D) https://orcid.org/0000-0002-8375-4611

Department of Philosophy, Room C43 Humanities Building, NG7 2RD Nottingham, United Kingdom

\stefano.predelli@nottingham.ac.uk

(C) The Author. Journal compilation (c) The Editorial Board, Organon F.

This article is distributed under the terms of the Creative Commons Attribution-NonCommercial 4.0 International Public License (CC BY-NC 4.0). 
more widely studied realizations of so-called non-truth-conditional meaning, as in the cases of register or derogation mentioned throughout this essay. Indeed, at least among us, the most likely candidates for anything in the vicinity of taboo are certain coarse expressions, and/or certain instances of racial or ethnic slurs. Yet, as I explain in what follows, taboo maintains a distinctive dimension: the conventional regularities responsible for the taboo status of an expression occupy an idiosyncratic niche, separate both from the classic treatments of truth-conditions and from the more recent semantic frameworks for expressives, honorifics, and all that goes with them.

To anticipate, taboo expressions are unmentionable expressions: what warrants a negative reaction to taboo words is their sheer display, that is, their mere occurrence. And so, their charged status derives from the presence of their tokens, including realizations within quotation marks or merely accidental occurrences. If, as it seems plausible, the taboo status of an expression is part and parcel of its conventional profile, it follows that the conventions in question must belong to areas of inquiry other than those traditionally covered by semantics - at least on a standard understanding of semantics as the study of conventional meaning, in its truth-conditional and non-truth-conditional guises.

In section one, I swiftly sketch certain features of current semantic theorizing, with particular attention to the non-truth-conditional domain. I do so for two reasons: as a preliminary background for the aforementioned partial relationships between these phenomena and taboo, but also as a term of contrast intended to highlight taboo's most intriguing idiosyncrasies. I propose a preliminary analysis of the peculiarly unmentionable status of taboo words in sections two and three, where I focus on the relationships between taboo, pure quotation, and related phenomena. Section four ventures a positive hypothesis: some aspects of the conventional profile of an expression, first and foremost its taboo status, are properties that belong in the province of the theory of action, rather than of semantics. Section five wraps things up with a few tentative remarks on the characteristic effects of the actions in question, taking as my starting point the idiosyncratic role of taboo within the study of conversational exchanges. 


\section{Non-truth-conditional meaning}

One's utterances can be subjected to a straightforward form of criticism, in the sense that what they encode happens to possess undesirable properties. So, a speaker may be chastised for uttering falsehoods, for asserting what she does not believe to be the case, or for putting forth an uninformative or irrelevant claim. Or else, she may be criticized for revealing information that should have been kept secret, or for speaking of a subject which ought not to be brought up in polite company. Yet, in other cases, the object of our normative assessment seems to be more closely related to one's mode of expression, rather than to the properties of encoded content: what has been said may well have been true, relevant, or interesting, but the way in which that content has been presented is judged to be offensive, inappropriate, or objectionable.

The justifications for these sorts of assessments presumably ensue from significantly different considerations. For instance, falsehood, insincerity, and irrelevance apparently invoke normative constraints other than those in place for our disdain towards profanities or offensive categorizations. Yet, at least according to widespread consensus, the source of these outcomes remains within the domain of semantic inquiry: modulo the distinction I am about to mention, both what an expression encodes and the aforementioned additional effects achieved by its use depend on the conventional properties naturally categorized as parts of its meaning.

The distinction that I have in mind is familiar enough: certain effects of the employment of an expression ensue from a dimension of conventional meaning that is different from the type of meaning responsible for its truthconditional contributions. Cases of register, honorifics, and slurs are perhaps the most widely discussed exemplars in this respect. So, intuitively, my use of 'tummy' at the doctor's may well contribute to true and informative information about my health, but it remains inappropriate qua exemplar of so-called Child Directed Speech, that is, as an instance of a type of register unsuitable for the interaction among adults. By the same token, the description of a German national by means of 'Kraut' may well be accurate 
and relevant, while remaining an appropriate target of disapprobation from the viewpoint of non-xenophobic decency. ${ }^{1}$

This intuitive divide has spurred a lively and fruitful semantic debate, focused on the peculiarity of the kind of meaning responsible for outcomes of register, coarseness, slurring, and all the rest. The buzzwords here are familiar enough and need not be rehearsed here: unlike more familiar forms of meaning, the conventions in question engender peculiar outcomes of nondisplaceability or projection, they play a non-at-issue role in the economy of conversation, and/or they display peculiarly expressive characteristics. Accordingly, as widespread philosophical jargon puts it, conventional meaning distributes along two different dimensions: a truth-conditional dimension responsible for the contribution of truth-conditionally relevant content, and a non-truth-conditional aspect devoted to those other peculiarities in an expression's conventional profile. ${ }^{2}$

Two aspects in this research program are worthy of note. The first decrees that issues of register, derogation, and all the rest ensue from meaning. The second focuses on the type of meaning it is. It is this second issue that has received most of the attention in the current literature: non-truth-conditional meaning is meaning all right, but it is a meaning of a special sort,

1 On register and related issues see for instance (Cruse 1986), (Allan 1990), and (Allan and Burridge 2006). For an influential essay on honorifics, see (Harada 1976); see also (Holmes 1992). For a sample of the discussion of derogatory terms, see (Potts 2003), (Hom 2008), (Richard 2008), (Williamson 2009), (McCready 2010), and (Anderson and Lepore 2013). For a study of the relationships between slurs and register, see (Diaz-Legaspe et al. 2020) and, for my own views on these matters, see (Predelli 2013)

2 The labels are not entirely perspicuous. At least in some views, what falls under the non-truth-conditional side is explicable in terms of truth-evaluable content, as in the case of 'Kraut' and the content that the speaker disparages Germans. Still, even in those views, this type of information is extraneous to the truth-conditions of, say, 'Angela is a Kraut', thereby providing at least partial justification for the standard description of its source as 'non-truth-conditional'. Regarding (different versions of) this paradigm see, among many, (Kaplan 1999), (Kratzer 1999), (Potts 2003), (McCready 2010), and (Gutzmann 2015); for my own views see (Predelli 2013). For discussions of non-displaceability see in particular (Kratzer 1999), (Potts 2003), (Sauerland 2007), (Amaral et al. 2007), and (Simons et al. 2010). 
worthy of being unveiled in all its multifarious manifestations. The starting point of the ensuing debates, namely the semantic dignity of the non-truthconditional dimension, is often accepted without further ado. But here, presumably, the proof is in the pudding: a non-truth-conditional dimension of meaning may safely be taken on board, as long as its yields desirable and theoretically fruitful outcomes.

For the record, for me, the pudding is worth the effort. In particular, the non-truth-conditional dimension apparently gives rise to phenomena and regularities that mirror, mutatis mutandis, those ensuing from more familiar sources of meaning. For instance, 'Angela is a Kraut but I never derogate Germans', though possibly true, seems to engender a tension most naturally explainable in terms of the contrast between the derogation included in the meaning of 'Kraut', and the content encoded in the second conjunct. Or else, in Italian, 'ti ho invitato a pranzo' ('I treated you [informal] to lunch') apparently bears some close relationship to 'the speaker is in a relation of familiarity with the addressee', even though it does not entail it.

And so, without further ado (and without argument) I happily go along with the familiar multi-dimensional approach to conventional meaning and to semantics. For me, then, 'stomach' and 'tummy', 'German' and 'Kraut', or, to cite an example that will play some role in what follows, 'to copulate' and 'to fuck' are truth-conditionally on a par, but they are not synonymous: by virtue of their meaning, the latter are instances of, respectively, Child Directed Speech, slurring, and coarseness. I accept all of this with nonchalance because my topic is not non-truth-conditional meaning, but the contrast between the dimensions of meaning to which I have alluded thus far and a different property of certain expressions. That property is the protagonist of this essay, namely taboo.

\section{Towards taboo}

The last example in the foregoing paragraph was not out of place in an academic journal: coarseness, the phenomenon exhibited by 'fuck', is surely an appropriate instance of non-truth-conditional meaning, side by side with register, honorifics, or derogation. It is, unsurprisingly, a word that has 
received the attention it deserves, including a monograph with essays directly devoted to it and to related affairs such as 'up yours' (Zwicky et al. 1971). In its adverbial form, it even appears in the title of an article in the academically dignified journal Theoretical Linguistics, unsurprisingly in an issue devoted to non-truth-conditional meaning in all of its manifestations (Geurts 2007).

Of course, neither I nor the authors of those essays inappropriately abandoned the terse register required for academic publication. In a nutshell, we all freely mentioned a coarse expression, but we refrained from using it. And yet, that word probably stood out in my list of specimens of the non-truthconditional domain. Of course, only the prissiest of readers would have been inclined to chastise my display. Still, even my most blasé audience did not fail to note its colourful appearance. Even dignified linguists such as the contributors to the aforementioned collection, though officially engrossed in the linguistic properties of 'fuck', did not conceal the transgressive gusto with which they put that expression on the printed page. ${ }^{3}$

This phenomenon is even more apparent when what is at issue is not what most of my readers are likely to consider a minor infraction of proper decorum. Derogatory terms with a history and potency much stronger than my relatively tame 'Kraut' resist unfettered mention to a greater extent than instances of coarseness, and they do so on the basis of a normative stance grounded on less superficial principles. I remain confident that, at most, mention of 'fuck' puts a cursory smile on some readers' lips. Other more alarming instances may in the end legitimately appear within quotation marks. Still I, and for all I know most of the students of slurs, steer away from causing offence by listing as their exemplars mild-mannered affairs such as 'Kraut' or, in Michael Dummett's case, downright antiquated exemplars such as 'Boche' (Dummett 1973).

3 In her discussion of slurs and offensiveness Renée Bolinger notes how "there is still something ... offensive about listing ... slurs explicitly" (Bolinger 2017, 443), and how "in some cases a speaker may rightly be censured for directly mentioning the slur" (Bolinger 2017, 451). Her topic is, of course, importantly different from mine: here, coarseness and slurs only occur as negotiable evidence of the limited forms of linguistic taboo available in our society. But the recognition of a certain 'resistance to mention' remains apt. 
It may be argued that all of the above indulges in excessive delicacy, a puerile fascination with the sheer sight of 'fuck' or, in the case of those most distasteful racial slurs, yet another case of political correctness gone crazy. That may, in the end, be the case. But it is a case that needs to be made. The question whether 'fuck' may at all be mentioned in an academic journal may well be replied in the positive, but it remains an intelligible question, unlike, say, the question whether one may mention 'rabbit' or 'Aristotle'. And the question whether this tolerance ought to extend to other instances is one that should not be taken unreflectively.

This peculiarity of the expressions under discussion, that is, their noteworthy occurrence within mention, is further testified by the existence of conventionalized locutions that designate those words without indulging in their displays. For instance, although I could refer to a common coarse designator of sexual activity by enclosing that verb within quotation marks, I could more delicately have done so by using the dedicated description 'the f-word'. No prizes for guessing its designatum: that description is properly in the singular, and what it designates is neither 'French' nor 'fries'. ${ }^{4}$ Similarly, for any moderately informed contemporary speaker, no guessing is required when it comes to 'the n-word', a description that pursues the wonders of mention without indulging in spelling out the unmentionable.

These features of 'fuck' and of particularly charged racial slurs deserve further attention. They are, in a sense, conventional: the distasteful aspects ensuing from the appearance of that four-letter word are surely not natural properties associated with its sound or with the shape of its written form. And yet, these are conventional features that do not fit the semantic frame of mind with which most of us approach register, derogation, or coarseness - or, even more clearly, designation or entailment. That they do not is testified by the very phenomenon to which I have called attention: their resistance to pure quotation.

After all, in a sense, pure quotation is a device designed so as to absorb meaning away. And so, in using the six-character quotational term "fuck" (that is, 'fuck' flanked by quotation marks), you neither speak of sexual intercourse nor engage in coarse verbal behaviour. At the very least: pure

4 See (Hughes 1991), (Harris 1987), (Davis 1989); see also (Zwicky 2003). 
quotation isolates you, the speaker, from the truth-conditional and nontruth-conditional commitments associated with what occurs inside the quotes. From the viewpoint of what is being used, then, the result of appending quotation marks is not a function of any of the semantic properties of that to which the quotes are appended. And so, Quine may perhaps have exaggerated the semantic inertia achieved by pure quotation when he proposed that "cat' occurs in "cat" no more interestingly than it does in "catatonic'. ${ }^{5}$ Yet, semantic inertia remains the name of the game, as testified by the well-formedness of instances where what is included in quotation marks is not a well-formed expression at all, as in the unobjectionable sentence 'xrt' is not an English word'. And so, the connotations of 'fuck' that still reverberate once that term is merely being mentioned must lie on a plane importantly different from that appropriate for all the dimensions of meaning to which I have alluded above, be they truth-conditionally significant properties or instances of non-truth-conditional meaning.

Quine's 'catatonic' is telling in this respect, since noteworthy repercussions may ensue even in cases other than when the mentioned term is being displayed in all of its glory, with those barely noticeable punctuation signs on either side of it. The well-known story of 'niggardly' has generated a lively political debate on either side of the spectrum. ${ }^{6}$ Regardless of the position one may wish to take in that debate, its existence indicates that there is an issue to be discussed - that is, that even accidental or only remotely related tokens may need to be handled with care. I have heard that 'donkey' became a popular substitute for 'ass' due to the desire to avoid expressions phonetically close to 'arse' (Hughes 1991, 19). I do not know whether that story is true, but it is not in principle unintelligible.

I think it was Kaplan who once remarked that decent semanticists ought to be able to spell out the meaning of xenophobic slurs in non-xenophobic language. Indeed they can: 'Kraut' designates Germans and it expresses

5 On the idea of semantic inertia see, for instance, (Davidson 1979) and (Cappelen and Lepore 2007); for my own views on pure quotation, see (Predelli 2009).

${ }_{6} \quad$ See the New York Times, 31 January 1999. Incidentally, in Bolinger's contrastive analysis of slurring and offensiveness, "to use the quotation name [e.g. "fuck"] rather than an available alternative [e.g. 'the f-word'] ... warrants offense" (Bolinger 2017, 452). 
disdain towards them, I may say. The details may be incorrect, but my attitude is untarnished, since I did not indulge in the use of the analysandum, as I would in standard Tarskian biconditionals such as: 'snow is white' is true iff snow is white. Similarly, I can surely provide a terse and not at all impolite analysis for 'fuck', as in, say: 'fuck' designates sexual intercourse and belongs to the coarse register. And yet, 'fuck' and its ilk put the student of language in a perilous situation. The referent, sexual intercourse, and the coarseness with which it is designated, are apparently neutralized when that word is displayed within quotation marks. Still, that very display suffices for the presence of those additional effects.

Something then remains that, metaphorically speaking, scopes out even of pure quotation. I refer to this aspect of an expression's profile as its taboo status, and I proceed with a few remarks on taboo in the remainder of this essay.

\section{Taboo tokens}

Our normative assessments of utterances generally involve a worldly dimension, side by side with the genuinely linguistic features of an expression. So, 'London is in France' may be chastised as being false because it says that London is in France, because London is not in France, and because the speaker was in a situation where true talk was required. 'Io ti ho invitato a pranzo' may be criticized as impolite when directed to an adult stranger because, by virtue of its Italian meaning, 'ti' is familiar, and because, in our society, adult strangers are not to be addressed in a familiar register. Or else, mutatis mutandis, 'Angela is a Kraut' elicits our disapproval because it derogates the Germans and because, in reality, derogation is unjustified or downright impermissible. And so, at least in principle, you may try to escape those accusations while maintaining your allegiance as an English or Italian speaker by attempting to change the world: you relocate London, you protest that you were not really asserting anything about actual geography, you promote a reform of our attitudes towards adult strangers, or you argue that anti-German prejudice is justified.

In some sense, taboo is a more direct affair: the criticism incurred by the violation of a taboo simply ensues from the fact that, in the relevant 
linguistic community, that word is being designated as taboo. You may well rejoice in that criticism, and you may enjoy your status as a rebel. But, if you utter a taboo word, you do not cease to be a target of disapprobation unless you relinquish your position as a member of that linguistic community.

That is not to say that the taboo status of an expression is utterly disentangled from the truth-conditional and/or non-truth-conditional aspects of its meaning. Presumably, some communities decree that, say, certain words for the divinity are taboo because they are privileged expressions for a being whose metaphysical status far exceeds that of anything that is a proper subject for human conversation. That is, they identify taboo expressions for reasons eventually having to do with the nature of their designatum, that is, for reasons related to their truth-conditional meaning. Or else, perhaps, 'fuck' ended up as taboo partly because of its connections with the non-truth-conditional aspects of its meaning, in a seamless shift from expressions that ought not to be used in polite company to words that should not even be mentioned. Indeed, in all likelihood, racial slurs such as the nword derive their forbidden status both from the hideous historical oppression suffered by its designatum, and from the venomous history of derogation in the Western world. In this respect, it is hardly an accident that 'Kraut', 'wop', or 'limey' did not follow its destiny, and that they remained derogatory but non-taboo expressions.

And so, taboo may well occasionally (or perhaps even inevitably) have ensued from historical processes grounded on an expression's designatum, on its non-truth-conditional meaning, or on something of both sorts. Yet this much is not equivalent to the denial of a distinctive niche for the conventional dimension of taboo. The contrast with truth-conditional meaning is patently obvious: truth-conditionally indistinguishable expressions may differ in their taboo status, as in the case of unobjectionable uses of 'copulate' for sexual intercourse. And so, certain noteworthy properties of the object or action or event that is being spoken about may perhaps have played a role in the generation of taboo, but they hardly suffice. The matter is no less clear when it comes to non-truth-conditional meaning: 'screw', in its use for sexual intercourse, is (or may well be) as coarse as 'fuck', but it is not (or need not be) taboo. And 'spook' is (or may well be) as derogatory 
as the n-word, but its mention hardly elicits the same sort of sentiments. And so, coarseness, derogation, or other potentially alarming facets of nontruth-conditional meaning may lie behind the history of certain terms as taboo, but they do not bear the entirety of the explanatory burden.

More importantly, the conceptually distinctive features of taboo remain in place even if the contrasts mentioned in the foregoing paragraph are called into question on empirical grounds. And so, taboo's reasons are varied, and are in no way limited to expressions that deal with delicate subjects, or that begin their life in the coarse or derogatory arenas. They may, in fact, be utterly arbitrary motives, letting one expression go while forbidding the occurrence of one that is fully synonymous with the first, that is, while prohibiting a word that is indistinguishable from the truth-conditional and non-truth-conditional level alike.

The arbitrariness of taboo extends to our very interaction with the incriminated words. Certain practices forbid the spoken occurrence of an expression while allowing its being written down, perhaps as in Maimonides' intimation that 'only in the Temple is the name [of God] recited as it is written' (Laws of Prayer and Priestly Blessings, 14:10). I cannot claim competence with the proper interpretation of the great Sephardic philosopher, but it is at least conceivable that what he was after is the intimation that a certain word may harmlessly be tokened in its written form, but that it may not be spoken, or at least not 'recited as it is written'. Even more surprisingly, the relationships between an expression and its involvement in taboo may have to do not with the prohibition that it be pronounced, written, or tokened in any other form, but rather that it be erased, as in a proscription presumably stemming from no lesser source than Deuteronomy: 'you shall destroy [Pagan gods'] names from this place, [but] do not do this to God' (Deuteronomy 12, 3-4).

These scenarios may well be rather distant from the sort of linguistic dictates with which most of us are familiar. Yet, they are instructive to a much greater extent than the giggles engendered by the repeated mention of 'fuck' among a group of adolescents. What is instructive, in particular, is the deliberate sloppiness of my exposition in the paragraph above. Surely, if what taboo forbids is, say, the spoken occurrence of an expression, it is not that expression itself that is that practice's main target, but its verbal 
tokens. Equally surely, expressions are not even the sort of thing that can be erased, since what is erased is a token, not the expression itself. And so, the taboo status of an expression must be interestingly related to its tokening, in ways that are more direct and illuminating than the limited significance of tokens in the study of its semantic meaning.

Returning to more familiar instances, then, the Kaplan-inspired project of a neutral analysis of coarse or derogatory terms inevitably breaks down when it comes to taboo. Or, at the very least, it breaks down when that analysis is being carried out: my speaking of the properties of 'fuck' need not indulge in an undesirable register, but it violates the dictates of taboo. And it does so inevitably, since any pronouncement as to the properties of 'fuck' must start with a specification of its object, that is, with the production of the incriminated token. Similarly, taboo's apparent 'scoping out' of quotation results from the unavoidable layout for quotational terms. So, "xrt" (the result of appending quotation marks to 'xrt') refers to a threeletter string precisely by virtue of the fact that 'xrt' occurs within it, that is, by virtue of the fact that it is tokened as part of the tokening of that five-character affair. And "fuck" mentions a certain English four-letter word precisely by virtue of displaying that four-letter sequence as its proper part. Quotation may well be a fruitful tool for unveiling certain characteristics of taboo, but what does the trick, there, is the very format for its realization, the occurrence of the incriminated form.

It is thus unsurprising that the accidental occurrences that I have mentioned above, as in the case of 'niggardly', may cause alarm to those sensitive to the taboo status of certain expressions. The ailurophobic may have no qualms with 'catatonic', but those who attribute taboo status to 'cat' may legitimately opt for a different designation of unresponsive stupor. And, in relation to the aforementioned distinctions between different forms of tokening, one's distress may be generated by (accidental or not so accidental) occurrences that are only phonetically in the vicinity of the incriminated term. I have heard of an overly sensitive teacher of French who refrained from revealing to her students the noun for seals, 'phoque', due to its phonetic vicinity with 'fuck'. The sacrifice of her pedagogical mission on the altar of a minor taboo is unforgivable, but her motive remains comprehensible. 


\section{Taboo and semantics}

In the first parts of this essay I alluded to the distinctive role of taboo as a part of an expression's conventional profile that is independent from what I called its 'semantic meaning', that is, a part of meaning unamenable to the application the standard tools of semantic analysis. The idea that taboo is intimately connected with the process of tokening helps to shed some light on this vague idea.

In a famous passage in Demonstratives Kaplan highlighted the distinction between the occurrence of an expression (that is, the "combination of an expression and a context") and an utterance of it: the idea of an utterance comes "from the theory of speech acts," whereas the notion of a sentence-in-a-context derives "from semantics" (Kaplan 1989a, 522). Kaplan's use of 'speech acts' is closely related to the act of speaking, that is, to the event of tokening. Indeed, the reason why that distinction is important is that the semantic study of meaning ought to abstract away from the accidental regularities governing tokens. For instance, "utterances take time and utterances of distinct sentences cannot be simultaneous," but this physical inevitability ought to be kept at bay for the purposes of semantics: "we do not want arguments involving indexicals to become valid simply because there is no possible context in which all the premises are uttered, and thus no possible context in which all are uttered truthfully" (Kaplan 1989a, 522). This idea is reiterated in his later commentary, Afterthoughts, in terms of a telling mentioned slogan: "semantics [is] concerned not with the vagaries of actions, but with the verities of meaning" (Kaplan 1989b, 584-5). Once again, the features he deems to be persona non grata in semantic society derive from the physical or metaphysical structure of tokening: "utterances take time, and are produced one at a time; this will not do for the analysis of validity" (Kaplan 1989b, 584). ${ }^{7}$

And yet, there is no reason why features of this sort, though apt examples of Kaplan's methodological recommendation, ought to exhaust the domain for 'the theory of speech acts'. And so, by all means, let us ground

7 For my developments of Kaplan's methodological advice, see (Predelli 2005) and (Predelli 2013). 
our study of truth-conditional and non-truth-conditional meaning on occurrences, rather than utterances. And let us do so in order to abstract away from, among other things, the facts that utterances take time, that they involve the exercise of the mouth or the hand, or that they are inevitably performed by intelligent beings. But more besides may need to be swept aside: these non-conventional, natural features of the tokening act need not be all there is that needs to be expunged from the proper domain for semantics. In particular, other aspects of the tokening process may well ensue from conventional injunctions, in particular from decisions that do not affect tokening in general, but the tokens of particular expressions. Taboo, a conventional aspect of certain expression, apparently falls on that side of the divide, and it firmly belongs among "the vagaries of action" rather than to "the verities of meaning."

A clear counterpart of all of this are the different targets for our normative assessment of an utterance. Those that are likely to catch the semanticist's attention are those ensuing from the properties associated with occurrences, that is, eventually, with sentences in a context. From the perspective of Demonstratives, those are the properties ensuing from character, that is, from truth-conditional meaning. But there are no reasons why nontruth-conditional features ought not to feature here as well. And so, as mentioned at the beginning of this essay, an utterance may be chastised for being false, redundant, or contradictory. Or else, for being derogatory, in the wrong register, or impolite. And if it is censured for any of these reasons, it is so because it is an utterance representable in terms of a sentence that is primarily responsible for bearing those meaning-related properties. The discussion of the relationships between taboo and the tokening process indicates that matters are different when it comes to this phenomenon. There may well be nothing objectionable in calling the taboo status of an expression a part of its conventional profile, at least in the sense of being an aspect of that needs to be mastered by its competent users. But there are reasons for resisting a fully-fledged commitment to 'meaning' in this case: what is at issue is a convention that pertains not to an expression in abstracto, but to the action of tokening it.

In this sense, the study of taboo falls squarely within a normative theory of action, albeit, in our case, the sort of action that is of interest from the 
viewpoint of language. Or else: a particular aspect of the conventional profile of certain expressions has little to do with anything that is of semantic concern, be it propositional encoding, truthful description, or the sort of expressive outcomes apparently engendered by virtue of non-truth-conditional meaning. This conventional dimension is rather fully captured from the viewpoint of a theory of linguistic action, that is, a theory of the sort of inter-personal coordination characteristic of conversational exchanges.

\section{Concluding remarks: the power of taboo}

The classic framework for the study of conversational moves focuses on their effects on common belief, that is, on a certain class of propositions. For instance, an assertoric and literal utterance of $\mathrm{s}$ apparently results in the proposal that $\mathrm{p}$ be added to common belief, where $\mathrm{p}$ is the proposition encoded in s. ${ }^{8}$ The literature on non-truth-conditional meaning has contributed to an expansion of this model, generally directed towards a more nuanced and structured picture of conversation. For instance, an utterance of 'Angela is a Kraut' may well engender effects related to the speaker's disdain for Germans, but it arguably proposes that these effects be recorded at a level other than that appropriate for an utterance of, say, 'Germans are intrinsically unworthy of respect'. ${ }^{9}$

The details here are important and independently interesting, but they may safely be set aside here. What matters in the picture sketched above is an assumption that affects the truth-conditional and non-truth-conditional aspects of the uttered expression: the act of tokening intervenes in the economy of conversation precisely insofar as it is an act involving the presentation of a meaning-bearing affair, in the semantic sense of that term. And so, a certain enrichment of the conversational record ensues from my token of 'London is in England', precisely because the truth-conditional meaning of what I uttered eventually yields a particular proposition. Or

8 See (Stalnaker 1999) and (Stalnaker 2014), and the considerable related literature; on the idea of assertions as proposals, see (Farkas and Bruce 2010).

9 For discussions of the multi-layered nature of conversation see, for instance, (Roberts 1996), (Portner 2007), (Farkas and Bruce 2010), and (Anderbois et al. 2015). 
else, something of a different nature happens when I token 'Angela is a Kraut', but that too stems from my words' semantic profile, in this case, at least in part, their non-truth-conditional meaning.

In this picture of conversation, then, the tokening process intervenes at best as something that is inevitable for creatures of our kind, but that is, in and of itself, of little significance. In other words: the manifest act of tokening is there all right, but it is there only qua manifest exemplification of an affair endowed with truth-conditional and/or non-truth-conditional meaning. The case of taboo, on the other hand, forcefully invites us to reconsider our traditionally dismissive attitude towards the nitty-gritty of the marketplace: the sheer token may well be unaccompanied by any noteworthy semantic effects, as when it is merely mentioned, and yet reverberates with all of its force.

A thing done cannot be undone. From this metaphysical triviality comes the potency of taboo. Recall, as a term of contrast, the classic take on assertoric conversational moves as proposals of propositional enrichment. They are proposals that, clearly, may not in the end make it to common belief: 'that is false', you protest, thereby preventing our exchange from taking that claim on board. Non-truth-conditional affairs are notoriously harder to resist: as a rejoinder to 'Angela is a Kraut', your 'that is false' merely questions my attribution of nationality to that woman. And yet, thankfully, the xenophobe is not all-powerful: 'hey, wait a minute, that is not the way to characterize the Germans', you may protest. ${ }^{10}$ And so, in either case, all can be undone, either by appealing to standard conversational tools such as denial and rejection, or by questioning the suitability of certain conversational developments.

Not so with taboo, whose power far exceeds that of non-truth-conditional meaning. 'Fuck', you utter. And, from the viewpoint of taboo, there is no taking it back, since the source of taboo, namely the very act of tokening, is what it is and cannot be undone. The prevention of taboo calls for the most literal form of silencing, that is, for forcibly preventing that token to occur in the first place.

10 For applications of 'hey wait a minute' to issues of presupposition, see (von Fintel 2004). 
All of the above surely deserves fuller theoretical attention. I wrap things up with a modest conclusion, independent of many details in my vague gestures thus far. For me, taboo and its conversational role turn out to be a profitable object of inquiry, both for their independent interest and for their repercussions on those other matters of semantic interest, most notably coarseness and derogation. More importantly, taboo also exerts an interesting pressure on our customary understanding of the study of language. Even if its role in human society turns out to be of lesser urgency than many other areas of semantic inquiry, the metasemantic repercussions of taboo deserve to be studied with care.

\section{Acknowledgements}

Many thanks to the participants in the symposium Value in Language, hosted by the Slovak Academy of Sciences (March 29-31, 2021). A particularly emphatic thank you goes to Rob Stainton, who provided extensive and detailed comments on a first draft of this paper.

\section{References}

Allan, Keith. 1990. "Some English Terms of Insult Invoking Sex Organs: Evidence of a Pragmatic Driver for Semantics." In Meanings and Prototypes. Studies in Linguistic Categorization, edited by S. L. Tsohatzidis, 159-94. London: Routledge.

Allan, Keith, and Kate Burridge. 2006. Forbidden Words: Taboo and the Censoring of Language. Cambridge: Cambridge University Press.

Amaral, Patricia, Craige Roberts, and E. Allyn Smith. 2007. "Review of The Logic of Conventional Implicatures by Chris Potts." Linguistics and Philosophy 30: 707-749. doi.org/10.1007/s10988-008-9025-2

Anderbois, Scott, Adrian Brasoveanu, and Robert Henderson. 2015. "At-issue Proposals and Appositive Impositions in Discourse." Journal of Semantics 32 (1): 93-138. doi.org/10.1093/jos/fft014

Anderson, Luvell, and Ernie Lepore. 2013. "Slurring Words." Noûs 47 (1): 25-48. doi.org/10.1111/j.1468-0068.2010.00820.x

Bolinger, Renée Jorgensen. 2017. "The Pragmatics of Slurs." Noûs 51 (3): 439-62. doi.org/10.1111/nous. 12090

Cappelen, Herman, and Ernest Lepore. 2007. Language Turned on Itself. The Semantics and Pragmatics of Metalinguistic Discourse. Oxford: Oxford University Press. 
Cruse, D. A. 1986. Lexical Semantics. Cambridge: Cambridge University Press.

Davidson, Donald. 1979. "Quotation." Theory and Decision 11: 27-40. Reprinted in Inquiries into Truth and Interpretation, 79-92. Oxford: Clarendon Press.

Davis, Hayley. 1989. "What Makes Bad Language Bad?" Language and Communication 9 (1): 1-9. doi.org/10.1016/0271-5309(89)90002-5

Diaz-Legaspe, Justina, Chang Liu, and Robert J. Stainton. 2020. "Slurs and Register: A Case Study in Meaning Pluralism." Mind and Language 35 (2): 156-82. doi.org/10.1111/mila.12236

Dummett, Michael. 1973. Frege: Philosophy of Language. London: Duckworth.

Farkas, Donka F., and Kim B. Bruce. 2010. "On Reacting to Assertions and Polar Questions." Journal of Semantics 27 (1): 81-118. doi.org/10.1093/jos/ffp010

von Fintel, Kai. 2004. "Would You Believe It? The King of France is Back! (Presuppositions and Truth-Value Intuitions)." In Descriptions and Beyond, edited by Marga Reimer, Anne Bezuidenhout, 315-41. Oxford: Oxford University Press.

Geurts, Bart. 2007. "Really Fucking Brilliant." Theoretical Linguistics 33 (2): 20914. doi.org/10.1515/TL.2007.013

Gutzmann, Daniel. 2015. Use-Conditional Meaning. Oxford: Oxford University Press.

Harada, S. I. 1976. "Honorifics." In Syntax and Semantics Vol. 5, Japanese Generative Grammar, edited by Masayoshi Shibatani, 499-561. New York: Academic Press.

Harris, R. 1987. "Mentioning the Unmentionable." International Journal of Moral and Social Studies 2: 175-88.

Holmes, Janet. 1992. An Introduction to Sociolinguistics. London: Longman.

Hom, Christopher. 2008. "The Semantics of Racial Epithets." The Journal of Philosophy 105 (8): 416-40. doi.org/10.5840/jphil2008105834

Hughes, Geoffrey. 1991. Swearing: A Social History of Foul Language, Oaths, and Profanity in English. Oxford: Blackwell.

Kaplan, David. 1989a. "Demonstratives." In Themes from Kaplan, edited by Joseph Almog, John Perry, and Howard Wettstein, 481-563. Oxford: Oxford University Press.

Kaplan, David. 1989b. "Afterthoughts." In Themes from Kaplan, edited by Joseph Almog, John Perry, and Howard Wettstein, 565-614. Oxford: Oxford University Press.

Kaplan, David. 1999. "What is Meaning? Explorations in the Theory of Meaning as Use." (ms)

Kratzer, Angelika. 1999. "Beyond Ouch and Oops: How Descriptive Content and Expressive Meaning Interact." (ms) 
McCready, Elin. 2010. "Varieties of Conventional Implicature." Semantics and Pragmatics 3: 1-57. dx.doi.org/10.3765/sp.3.8

Portner, Paul. 2007. "Instructions for Interpretation as Separate Performatives." In On Information Structure, Meaning, and Form. Generalizations Across

Languages, edited by Kerstin Schwabe, and Susanne Winkler, 407-25. John Benjamins.

Potts, Christopher. 2007. "The Expressive Dimension." Theoretical Linguistics 33 (2): 165-98. doi.org/10.1515/TL.2007.011

Predelli, Stefano. 2005. Contexts: Meaning, Truth, and the Use of Language. Oxford: Oxford University Press.

Predelli, Stefano. 2009. "The Demonstrative Theory of Quotation." Linguistics and Philosophy 31: 555-72. doi.org/10.1007/s10988-008-9042-1

Predelli, Stefano. 2013. Meaning without Truth. Oxford: Oxford University Press. Richard, Mark. 2008. When Truth Gives Out. Oxford: Oxford University Press.

Roberts, Craige. 1996. "Information Structure in Discourse: Towards an Integrated Formal Theory of Pragmatics." In OSU Working Papers in Linguistics No. 49. Papers in Semantics, edited by Jae-Hak Yoon, and Andreas Kathol, 91-136. The Ohio State University.

Sauerland, Uli. 2007. "Beyond Unpluggability." Theoretical Linguistics 33 (2): 231-6. doi.org/10.1515/TL.2007.016

Simons, Mandy, Judith Tonhauser, David Beaver, and Craige Roberts. 2010.

"What Projects and Why." In Proceedings of SALT 20, edited by Nan Li, and David Lutz, 309-27.

Stalnaker, Robert. 1999. Context and Content. Oxford: Oxford Unievrsity Press.

Stalnaker, Robert. 2014. Context. Oxford: Oxford University Press.

Williamson, Timothy. 2009. "Reference, Inference, and the Semantics of Pejoratives." In The Philosophy of David Kaplan, edited by Joseph Almog, and Paolo Leonardi, 137-58. Oxford: Oxford University Press.

Zwicky, Arnold. 2003. "The Other F Word." Out 115: 82-4.

Zwicky, Arnold M., Peter H. Salus, Robert I. Binnick, and Anthony L. Vanek. 1971. Studies Out in Left Field. Defamatory Essays Presented to James D. McCawley on the Occasion of His 33rd Or 34th Birthday. Edmonton: Linguistic Research Inc. 